\title{
A PROSPECTIVE STUDY OF FRACTURE NONUNION OF CLAVICLE MANAGED BY INTERNAL FIXATION WITH OR WITHOUT BONE GRAFTING
}

\author{
K. V. Puttakemparaju1, Pandurangaiah Srinivas², Ramachandra S3, Karan Shetty4 \\ 1 Professor, Department of Orthopaedics, Bangalore Medical College \& Research Institute. \\ ${ }^{2}$ Assistant Professor, Department of Orthopaedics, Sri Devaraj Urs Medical College. \\ ${ }^{3}$ Assistant Professor, Department of Orthopaedics, Bangalore Medical College \& Research Institute. \\ ${ }^{4}$ Postgraduate Student, Department of Orthopaedics, Bangalore Medical College \& Research Institute.
}

\section{ABSTRACT}

\section{BACKGROUND}

Even today there is a dilemma whether clavicle fractures should be treated conservatively or surgically. Several factors predispose to nonunion like inadequate conservative treatment, fracture comminution, re-fracture, distal-third fracture, marked displacement or shortening of $>2 \mathrm{~cm}$ and primary open reduction. Generally, surgery is indicated in nonunion associated with pain and functional disability of the shoulder. Excellent rates of union have been reported after plating and grafting by many authors.

STUDY DESIGN: Treatment and Outcome Study.

\section{MATERIALS AND METHODS}

16 patients with clavicle nonunion were treated at our centre from 2008 to 2014. Pain was present in 14 cases and 12 patients had functional disability. 10 were hypertrophic type and 6 were of atrophic type. Lane and Sandhu radiology scoring system was used for assessing amount of callus and type of nonunion. Internal fixation was achieved by using locking compression plate ( 10 patients), recon plate ( 4 patients) and limited contact dynamic compression plate ( 2 patients). 7 received cancellous iliac bone grafting. Clinical outcome was determined by Constant score, etc. Results - Union was achieved in 15 out of 16 patients (93.75\%). The average time to union was 13.5 weeks. Fixation with Locking Compression Plates showed slightly better Constant score, (LCP: 82.88, recon plate: 80.25, LCDCP: 79) though not significant. There was significant improvement in pain and function after internal fixation as noted in the scores. The constant scores were better in the grafted group (83.12 Vs. 78.75).

\section{CONCLUSION}

Improvement in the shoulder function and pain relief was significant after internal fixation and achieving union in anatomical position and maintaining the length of clavicle. Use of plating is advisable in nonunion clavicle since it is having many advantages over intramedullary fixation. Locking plates provide better results since it contours to the curve of the clavicle with least chances of implant failure. Grafting improves the functional outcomes.

\section{KEYWORDS}

Fracture, Clavicle, Nonunion, Plating, Grafting.

HOW TO CITE THIS ARTICLE: Puttakemparaju KV, Srinivas P, Ramachandra S, et al. A prospective study of fracture nonunion of clavicle managed by internal fixation with or without bone grafting. J. Evolution Med. Dent. Sci. 2016;5(86):6384-6388, DOI: $10.14260 /$ jemds/2016/1444

\section{BACKGROUND \\ Even today there is a dilemma whether clavicle fractures} should be treated conservatively or surgically. Most were treated conservatively, because even severe radiographic malalignment would not influence functional results. ${ }^{1}$ Dissatisfaction is seen in $30 \%$ of patients due to the relatively high number of nonunions, residual deficits in shoulder strength and endurance, persistent pain and disappointing cosmetic results. ${ }^{2}$ Therefore, there is a tendency towards surgical treatment for displaced midshaft clavicular fractures. ${ }^{3}$

Financial or Other, Competing Interest: None.

Submission 05-06-2016, Peer Review 16-09-2016,

Acceptance 22-09-2016, Published 26-10-2016.

Corresponding Author:

Dr. K. V. Puttakemparaju,

Professor,

Department of Orthopaedics,

Room No. 34 A, Old OPD Block, Victoria Hospital,

Bangalore Medical College \& Research Institute,

Fort Area, Bangalore-560002, Karnataka.

E-mail: kvpkr@rediffmail.com

DOI: 10.14260/jemds/2016/1444
If there is no progression of union at 4-6 months clinically or radiographically, it is considered as clavicular nonunion. $4,5,6$ Tapered, sclerotic, atrophic bone ends at 16 weeks are also considered as nonunion. ${ }^{6}$ Neer described nonunion rates of $0.1 \%$ after conservative treatment and $4.4 \%$ after operative treatment. ${ }^{1}$

Several factors predispose to nonunion of the clavicle like inadequate conservative treatment and immobilisation, severity of trauma and fracture comminution 7,8 , re-fracture, distal-third fracture ${ }^{1,9}$, marked displacement or shortening of $>2 \mathrm{cms}$, soft-tissue interposition, and primary open reduction. 10,11

Nonunion can be either atrophic or hypertrophic type. Atrophic type is more common. Incidence being atrophic type $33 \%$, hypertrophic $20 \%$, mixed $7 \%$ and delayed union $40 \%$. Atrophic type is asymptomatic in the majority of cases.5,12 $3 / 4$ ths of symptomatic nonunions are seen in the midshaft and $25 \%$ in the lateral-third of the clavicle. ${ }^{9}$ Majority of the hypertrophic type require surgery, also most are symptomatic. ${ }^{5}$

Generally, surgery is indicated in nonunion associated with pain and functional disability of the shoulder. ${ }^{13}$ Other indications are displaced and shortened clavicular shaft 
fractures. ${ }^{14}$ Functional disability means difficulty in doing heavy manual labour, difficulty working for long hours, etc. Problems due to shortening occur since the shoulder will be shifted forwards and medially, which will lead to altered mechanics around clavicle, leading to pain, decreased range of motion, suboptimal functions and secondary osteoarthritis. Shortening can lead to a malposition of glenoid with abduction and overhead motion deficits. 15

Nonunion of the middle third of the clavicle are often treated surgically. ${ }^{13}$ Intramedullary fixation has disadvantages like hardware migration and soft tissue irritation at the insertion site. ${ }^{14}$ Achieving rotational control of the middlethird of the clavicle is more difficult with intramedullary device alone, particularly if associated with bone loss. ${ }^{10}$ Excellent rates of union have been reported after plating and grafting by many authors.5,6,7,16,17,18,19,20, Advantages over intramedullary fixation are improved rotational stability, ability to incorporate an intercalary graft and no fear of implant migration. ${ }^{21}$

Few authors did not find the need of bone grafts from the iliac crest and suggested plating alone, 22,23 especially in hypertrophic types of nonunions 7,24 and well-vascularised bone beds after local preparation. ${ }^{7}$ Bone grafts will hasten bone healing when nonunion clavicle is treated with plating and bone graft. ${ }^{7}$ In the case of larger bone defects with clavicle shortening, a tricortical bone was harvested from the iliac crest, whereas cancellous bone was used in smaller defects. ${ }^{7}$ Bone graft can be harvested either from the fracture site or iliac crest. 25

Since there is only limited evidence, further trials are warranted. Many trials had design features that carried a high risk of bias, potentially limiting the reliability of their findings. Hence, this study was done to evaluate nonunion of clavicular fractures treated surgically by plate fixation regarding improvement of pain and function.

\section{MATERIALS AND METHODS}

There were 16 patients with clavicle nonunions. Out of which 10 were hypertrophic type and 6 were of atrophic type. All these patients were treated at Victoria Hospital, Bangalore Medical College and Research Centre, Bangalore from 2008 to 2014. The mean age was 29 years (range 18 to 59 years). There were 13 male and 3 female patients. Comorbidities like DM were seen in 1 patient and hypertension in the same patient. 11 patients were treated conservatively initially and the rest had surgical fixation. The mechanisms of injury were accidents, sports or falls. The time between injury and surgery for nonunion was 8.13 months (range 4 months to 24 months). Preoperative radiographic score was done as per Lane and Sandhu scoring system ${ }^{18}$ (Table 1 ).

Pain was present in 14 cases, 12 patients had functional disability, 5 patients had $>2 \mathrm{~cm}$ displacement or shortening. None had neurovascular deficit. Inclusion criteria were age $>$ 18 years with symptomatic nonunion of fracture clavicle, $>2$ $\mathrm{cm}$ displacement or shortening and for those who gave informed written consent. Exclusion criteria were infection, malignancy, no informed consent. All surgeries were performed by first author. The standard technique of plating and freshening of nonunion ends was used. A horizontal skin incision was made along the superior side of the clavicle and centred over the nonunion site. The skin, platysma, and subcutaneous tissue were raised as one flap. The nonunion site was exposed, freshening of bone ends was done and medullary canal was opened and reamed with a drill. All were internally fixed with plates and screws applied over the superior surface. Intraoperatively, the surgeon decided whether a bone graft from the iliac crest was used. Graft was not put in hypertrophic nonunion and when well vascularised bone beds were achieved after local preparation. For smaller defects of less than $2 \mathrm{~cm}$, cancellous bone grafting from iliac crest was done. For larger defects of more than $2 \mathrm{~cm}$, tricortical iliac crest graft was applied. Intraoperatively, the length of the clavicle was measured using $\mathrm{C}$ arm and a measuring scale. Physiotherapy with a $90^{\circ}$ limited abduction of the shoulder for 6 weeks was advised for all. Patients were followed up at 6 weeks, 12 weeks, 3 months, 6 months, 12 months, 18 months and 24 months after the surgery. The range of movement and strength were recorded which was used to measure the Constant score.

Clinical union was said to be achieved if pain was absent, and no tenderness, no crepitus or abnormal mobility. X-rays were reviewed by two or more persons. Union was defined as complete bridging in anteroposterior view with obliteration of the fracture gap. Lane and Sandhu radiology scoring system was used for assessing amount of callus and type of nonunion. ${ }^{19}$ Preoperatively, 5 patients had score 0,3 had score 1,8 had score 2. Postop radiographic score (2 yr. followup) was compared with the preop score. Longterm results were reported after two years in all the 16 patients. Clinical outcome was determined by Constant score, DASH score, VAS score and SF-36.

For continuous variables, Mean and standard deviation (SD) were calculated, and for ordinal variables mean and median were calculated. The primary outcome was noted by the Constant score. Differences between the Constant score and a variable were tested by Student's $t$ in the case of data with normal distribution. The chi-square test was used in the analysis of contingency tables. A correlation between two variables was calculated by Pearson's coefficient $R$.

\section{RESULTS}

Internal fixation was achieved by using locking compression plate (10 patients), $3.5 \mathrm{~mm}$ recon plate ( 4 patients) and limited contact dynamic compression plate ( 2 patients). 6 received cancellous iliac bone grafting, 1 received tricortical iliac crest corticocancellous graft.

Followup of X-rays was 2 years. Union was achieved in 15 out of 16 patients (93.75\%) (Table 2). The average time to union was 13.5 weeks (Range 12 weeks to 24 weeks) (Fig. 1a, b, c). Further re-osteosynthesis was required in 1 patient after 12 months. At re-osteosynthesis it was treated with tricortical iliac crest graft and plating.

1 patient received tricortical graft and 6 had cancellous grafts. Followup was done up to two years. Though fixation with LCP showed slightly better score, (LCP: 82.88, recon plate: 80.25 , LCDCP: 79) there was no significant difference found between various fixation types in Constant scores. There was significant improvement in pain and function after internal fixation as noted in the Constant score, VAS score and other scores. The Constant scores were better in the grafted group (Constant score in grafted group 83.12, in non-grafted group 78.75). DASH scores were also better in the grafted group. The scores from SF-36 showed good results in all. Initial conservative or operative treatment $(p=0.63)$ showed no difference in scores. Two comorbidities affected the 
outcome, i.e. Constant score in the patient with two comorbidities was $70(\mathrm{p}=0.3)$. VAS improved significantly between preoperative evaluation and time of discharge, with a further decrease with time. Less shortening was seen when tricortical graft was used. $(0.4 \mathrm{~cm}$ vs. $1.4 \mathrm{~cm}$; $\mathrm{p}=0.10)$. A correlation analysis demonstrated only a mild negative correlation between clavicle length and Constant scores in all patients $(\mathrm{R}=-0.29)$, indicating that shortening of the clavicle was slightly associated with lower Constant scores. No significant correlation between range of motion and clavicle shortening was found in all patients. All the patients returned to their previous work. Implant removal was done in 12 patients after an average of 20 months.

In 1 patient, union failed after first surgery for nonunion. It failed to unite due to infection, it was managed conservatively initially. He required second surgery with plating and tricortical iliac graft. Union was achieved with consolidation after 12 months. Donor site pain was seen in 4 patients (50\%), which resolved with time. None of our patients had re-fracture after implant removal.

\begin{tabular}{|c|c|}
\hline Score & Radiologic Findings \\
\hline 0 & No Callus \\
\hline 1 & Minimal Callus \\
\hline 2 & Callus Evident but Healing Incomplete \\
\hline 3 & Callus Evident with Stability Expected \\
\hline 4 & Complete Healing with Bone Remodelling \\
\hline \multicolumn{2}{|c|}{ Table 1: Lane and Sandhu Scoring System } \\
\hline
\end{tabular}

Table 1: Lane and Sandhu scoring system. Score is given according to the amount of callus seen, stability expected and the remodelling findings in the X-rays.

\begin{tabular}{|c|c|c|}
\hline & $(n=10)$ & p value \\
\hline $\begin{array}{l}\text { Bone Consolidation } \\
\text { after the First Surgery }\end{array}$ & $\begin{array}{c}15 / 16 \\
(93.75 \%)\end{array}$ & 0.02 \\
\hline $\begin{array}{l}\text { Bone Consolidation } \\
\text { after Revision }\end{array}$ & $\begin{array}{c}16 / 16 \\
(100 \%)\end{array}$ & 0.16 \\
\hline $\begin{array}{c}\text { Lane and Sandhu Score } \\
\text { Preoperatively }\end{array}$ & 1.18 & 0.03 \\
\hline $\begin{array}{l}\text { Lane and Sandhu Score } \\
\text { after the first surgery }\end{array}$ & 3.56 & 0.05 \\
\hline $\begin{array}{l}\text { Lane and Sandhu Score } \\
\text { after Revision }\end{array}$ & 3.75 & 0.21 \\
\hline $\begin{array}{c}\text { Revision (No. of Patients/ } \\
\text { No. of Surgeries) }\end{array}$ & $1 / 1$ & 0.02 \\
\hline Time to Union (Weeks) & 13.5 & 0.02 \\
\hline $\begin{array}{c}\text { Time to Bone } \\
\text { Consolidation (Months) }\end{array}$ & 9.75 & 0.04 \\
\hline
\end{tabular}

Table 2: Union, Consolidation and revision rates. Statistics of consolidation, union and Lane and Sandhu scores are summarised in this table.

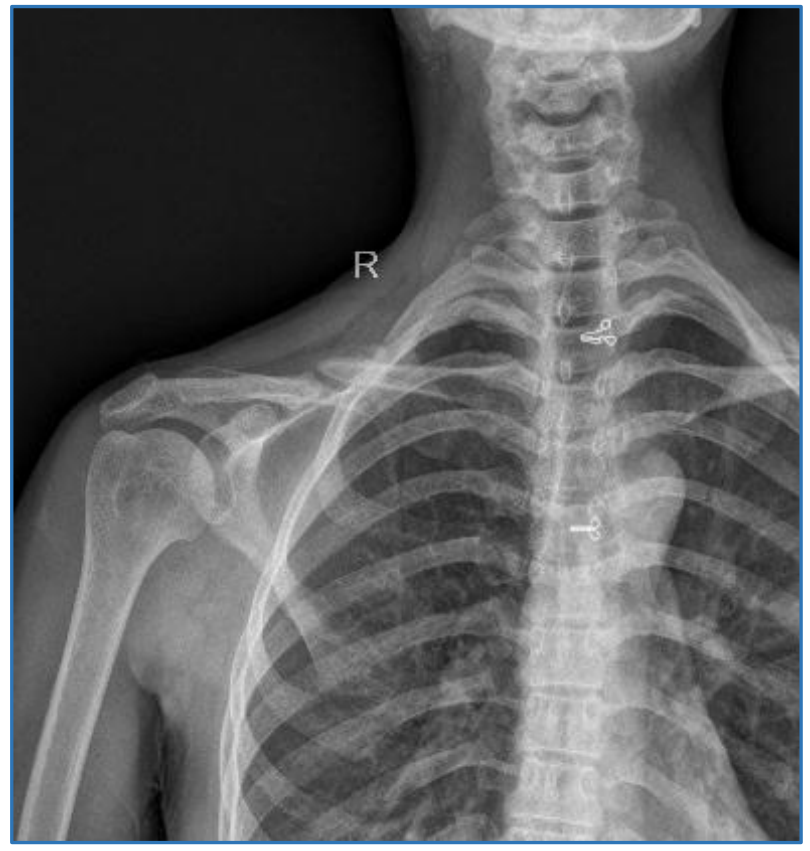

Fig. 1a: Preop

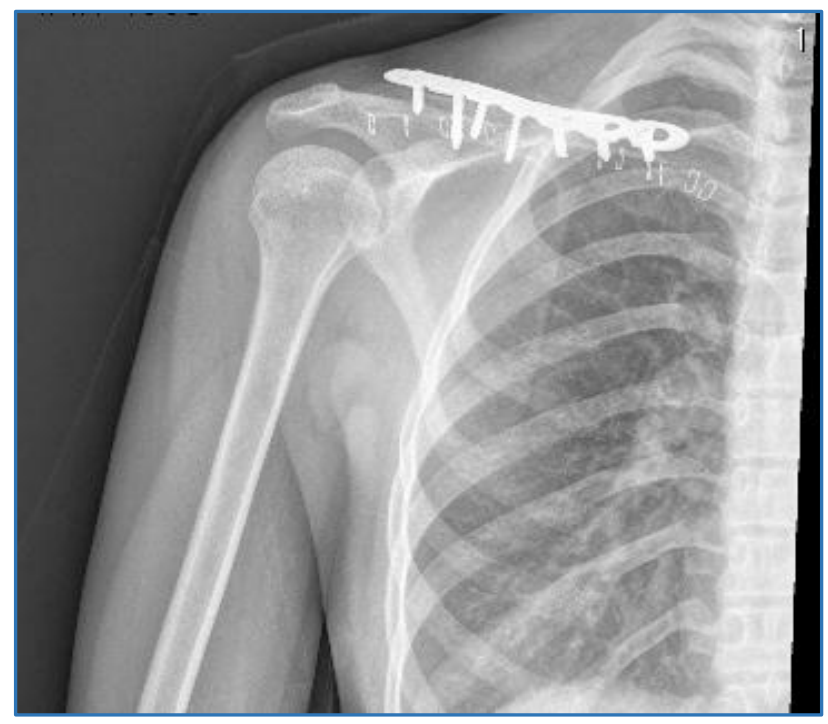

Fig. 1b: Postop

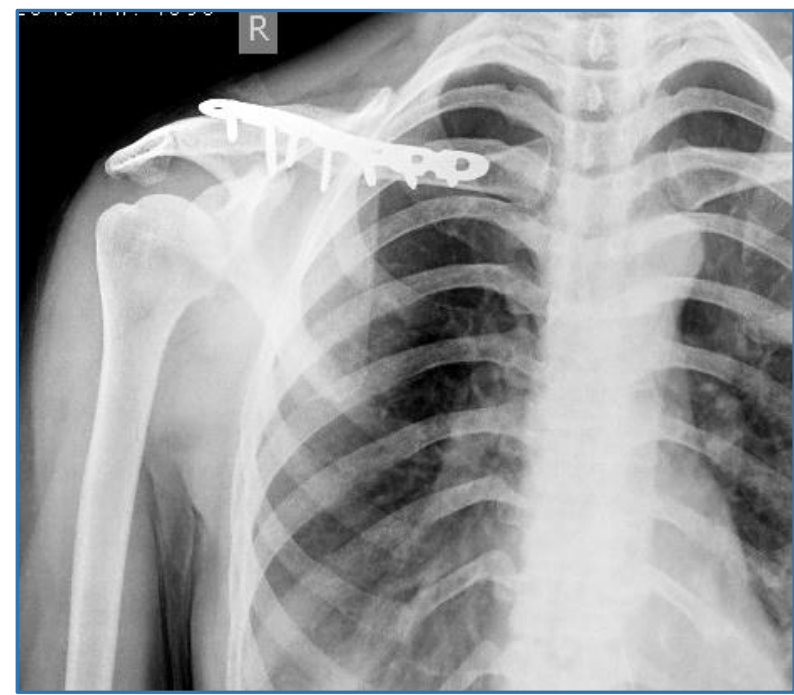

Fig. 1c: United 


\section{DISCUSSION}

Plate fixation has been a reliable and reproducible technique. ${ }^{26}$ In our study, all were fixed with plating. Intramedullary fixation has disadvantages like hardware migration and soft tissue irritation at the insertion site. ${ }^{14}$ Achieving rotational control of the middle-third of the clavicle is more difficult with intramedullary device alone, particularly if associated with bone loss. ${ }^{10}$ Lot of reports support the findings of our current study. Excellent rates of union have been reported after plating with or without grafting by many authors.5,6,7,16,17,18,19,20, Advantages over intramedullary fixation are improved rotational stability, ability to incorporate an intercalary graft (Most nonunions require freshening of fracture end resulting in gap), no fear of implant migration ${ }^{21}$ and early rehabilitation due to increased stability. Mullaji and Jupiter ${ }^{16}$ demonstrated use of the LC-DC plates in treating fractures, malunions and nonunions of the clavicle. Schnetzke ${ }^{7}$ used superior surface plates, either LCP, LCDCP or hook plates with no statistical difference between the plates. Outcome was not affected in either atrophic or hypertrophic types. In our study all were fixed on the superior surface. Time to union and outcome as measured by DASH scores was significantly better in nonunions treated with LC-DC plate versus DC plate fixation. ${ }^{19}$ Plate applied to the superior surface can act as a tension band, which enhances compression. Faraud et al 25 showed that stable fixation and bone graft for clavicle nonunion following failed conservative treatment is a reliable, well suited and effective treatment. Khan ${ }^{24}$ used LCPs and reported union in 11 patients with poor bone stock and achieved good functional outcome. The most common implants in current practice have been reported to be dynamic compression or titanium nails or locking plates specially designed for treating clavicle fractures.14,24 In our study Internal fixation was achieved by using locking compression plate (10 patients), $3.5 \mathrm{~mm}$ recon plate (4 patients) and limited contact dynamic compression plate (2 patients). Both dynamic compression plate and reconstruction plate have given equally good results, but with latter it is easier to give contour to the complex form of the clavicle. ${ }^{18}$ Low-contact dynamic compression plates appeared to be associated with significantly better upper-limb function throughout the year following surgery, earlier fracture union and return to work, and a reduced incidence of implantassociated symptoms when compared with a standard dynamic compression plate in 36 adults with symptomatic nonunion of the middle third of the clavicle. ${ }^{13}$

Endrizziet al $^{23}$ concluded that a bone graft might not be necessary in most cases of clavicle nonunion. He had used distant grafts in only three patients out of 43 patients. Good consolidation rates were found even in those whom distant grafts were not used. Bone graft can be harvested either from the fracture site or iliac crest. ${ }^{25}$ In the case of larger bone defects with clavicle shortening, a tricortical bone was harvested from the iliac crest, whereas cancellous bone was used in smaller defects. ${ }^{7}$ Jupiter and colleagues ${ }^{9}$ used bone grafts in 18 out of 21 patients and achieved success, by utilizing the osteogenic, osteoconductive and osteoinductive properties of iliac crest. In our study, 7 received cancellous iliac crest grafting and one received tricortical iliac graft. In Schnetzke et al $^{7}$ study, bone graft was used in Group 2 patients with high rates of union and good functional outcome. An intercalary bone graft is not required and would not result in unacceptable reduction in length after surgery. Seiler and
Jupiter ${ }^{27}$ specifically addressed the restoration of clavicular length in a more recent study; they used intercalary tricortical iliac crest bone grafts to treat clavicular nonunions with bony defects.

Preoperatively, they obtained a view of the contralateral clavicle to establish the normal length of the clavicle, and they determined the size of the bone graft by comparing the anteroposterior radiographs of each clavicle. They procured a tricortical iliac crest that was 1.5 times larger than the calculated defect. LCDCP was used.

The average time to union was 13.5 weeks (range 12 weeks to 24 weeks) which was similar to study by jones grant et al in which it was 15.6 weeks (range 7 to 34 weeks). Bone consolidation was determined by the Lane and Sandhu score preoperatively and after 2 years. The average time to consolidation was 9.75 months. It was similar in the study by Schnetzke in which Bone consolidation was determined by the Lane and Sandhu score preoperatively and after $2.2 \pm 1.8$ years, respectively. Here the average time to consolidation was $10.3+/-9.5$ months. $^{7}$

Complications of surgical treatments include wound infection or dehiscence, deep infection, and problems with the hardware used for fixation. In our study one case had infection and it was initially treated conservatively with antibiotics and regular dressings. Later second surgery was done with plating and tricortical grafting after 1 year. Finally it united. Hence, rate of infection was $6.25 \%$ which is similar to the studies described below. The rate of infection ranges from $0 \%$ to $18 \%,{ }^{28,29}$ and the rate of hardware irritation that requires part or total hardware removal ranges from $50 \%$ to $100 \% .26,28$ In our study, 8 patients required implant removal which is similar to the above studies. Other potential drawbacks of surgical interventions include scarring, complex regional pain syndrome, transient brachial plexus symptoms, implant loosening, nonunion and re-fracture after hardware removal, and hardware migration. ${ }^{28,29}$ We did not encounter these complications.

Data on the long term functional results is very limited. Bradbury et al 18 study had union in 31 of 32 patients with Constant score of 87 after 8 years. O'connor ${ }^{20}$ evaluated after 42 months. Most of the trials did not report on quality of life or return to previous activities. ${ }^{13}$

Strengths of this study is that it is reporting the gold standard treatment of plating for nonunion accepted by all and that locking plates were used which is the implant being used by most, unlike days of the past. Limitations are that it has not considered inferior plating, or nailing for comparison of outcomes. We have not reported on quality of life. Our study did not compare anterior vs. superior plating. To clear risk of bias due to flawed methods and data scarcity, further studies are warranted. We also advise that the results be verified by further prospective RCT studies.

\section{CONCLUSION}

Improvement in the shoulder function and pain relief was significant after internal fixation and achieving union in anatomical position and maintaining the length of clavicle. Use of plating is advisable in nonunion of clavicle because of many advantages over intramedullary fixation. Locking plate provide better results since it contours to the curve of the clavicle and gives stable fixation with least chances of implant 
failure. Grafting improves the union rates and also functional outcomes. Tricortical blocks may be used if the defect size is large.

\section{REFERENCES}

1. Neer C. Fractures of the clavicle. $2^{\text {nd }}$ ed. In: Rockwood CA, Green DP, (edr). Fractures in adults. Philadelphia: Lippincott Williams \& Wilkins 1984:707-13.

2. Hill JM, McGuire MH, Crosby LA. Closed treatment of displaced middle-third fractures of the clavicle gives poor results. J Bone Joint Surg Br 1997;79(4):537-9.

3. Smekal V, Oberladstaetter J, Struve P, et al. Shaft fractures of the clavicle: current concepts. Arch Orthop Trauma Surg 2009;129(6):807-15.

4. Craig EV. Fractures of the clavicle. In: Rockwood CA, Matsen FA, eds. The shoulder. Philadelphia: WB Saunders 1998:428-82.

5. Wilkins RM, Johnston RM. Ununited fractures of the clavicle. J Bone Joint Surg Am 1983;65(6):773-8.

6. Manske DJ, Szabo RM. The operative treatment of midshaft clavicular non-unions. J Bone Joint Surg Am 1985;67(9):1367-71.

7. Schnetzke M, Morbitzer C, Aytac S, et al. Additional bone graft accelerates healing of clavicle non-unions and improves long-term results after 8.9 years: a retrospective study. Journal of Orthopaedic Surgery and Research 2015;10:2.

8. Martetschlägerx F, Gaskill TR, Millett PJ. Management of clavicle nonunion and malunion. Journal of Shoulder and Elbow 2013;22(6):862-8.

9. Jupiter JB, Leffert RD. Non-union of the clavicle. Associated complications and surgical management. J Bone Joint Surg Am 1987;69(5):753-60.

10. Khan MA, Vakati SR. Management of clavicular non-union with plate fixation and bone grafting. Archives of International Surgery 2013;3(1):49-51.

11. Lenza M, Liu GD, Tong SL, et al. Operative versus nonoperative treatment for clavicle fracture: a meta-analysis. Int Orthop 2013;37(8):1495-500.

12. Jones GJ, McCluskey GM, Curd DT. Nonunion of the fractured clavicle: evaluation, etiology, and treatment. J South Orthop Assoc 2000;9(1):43-54.

13. Lenza M, Faloppa F. Surgical interventions for treating acute fractures or non-union of the middle third of the clavicle. Cochrane Database Syst Rev 2015;5:CD007428.

14. King PR, Ikram A, Lamberts RP. The treatment of clavicular shaft fractures with an innovative locked intramedullary device. J Shoulder Elbow Surg 2015;24(1):e1-6.

15. Andermahr J, Jubel A, Elsner A, et al. Malunion of the clavicle causes significant glenoid malposition: a quantitative anatomic investigation. Surg Radiol Anat 2006;28(5):447-56.
16. Mullaji AB, Jupiter JB. Low-contact dynamic compression plating of the clavicle. Injury 1994;25(1):41-5.

17. Boyer MI, Axelrod TS. Atrophic nonunion of the clavicle treatment by compression plate, lag-screw fixation and bone graft. JBJS Br 1997;79-B(2):301-3.

18. Bradbury N, Hutchinson J, Hahn D, et al. Clavicular nonunion. 31/32 healed after plate fixation and bone grafting. Acta Orthop Scand 1996;67(4):367-70.

19. Leupin S, Jupiter JB. LC-DC plating with bone graft in posttraumatic nonunions in the middle third of the clavicle. Swiss Surg 1998;4(2):89-94.

20. O'Connor D, Kutty S, McCabe JP. Long-term functional outcome assessment of plate fixation and autogenous bone grafting for clavicular non-union. Injury 2004;35(6):575-9.

21. Lazarus MD. Fractures of the clavicle. $6^{\text {th }}$ ed. In: Robert W Bucholz, Rockwood \& Green's Fractures in Adults. Lippincott Williams \& Wilkins 2006:1239.

22. Baker JF, Mullett H. Clavicle non-union: autologous bone graft is not a necessary augment to internal fixation. Acta Orthop Belg 2010;76(6):725-9.

23. Endrizzi DP, White RR, Babikian GM, et al. Nonunion of the clavicle treated with plate fixation: a review of forty-seven consecutive cases. J Shoulder Elbow Surg 2008;17(6):951-3.

24. Alam S, Prasoon S, Vikas G, et al. Locking compression plate in long standing clavicular nonunions with poor bone stock. Trauma-Injury Infection \& Critical Care February 2008;64(2):439-41.

25. Faraud A, Bonnevialle N, Allavena C, et al. Outcomes from surgical treatment of middle-third clavicle fractures nonunion in adults: a series of 21 cases. Orthop Traumatol Surg Res 2014;100(2):171-6.

26. Canadian Orthopaedic Trauma Society. Nonoperative treatment compared with plate fixation of displaced midshaft clavicular fractures. A multicenter, randomized clinical trial. Journal of Bone and Joint Surgery 2007;89(1):1-10.

27. Seiler JG, Jupiter JB. Intercalary tricortical iliac crest bone grafts for treatment of chronic clavicle nonunion with bony defect. J Orthop Tech 1993;1:19-22.

28. Bostman O, Manninen M, Pihlajamaki H. Complications of plate fixation in fresh displaced midclavicular fractures. J Trauma 1997;43(5):778-83.

29. Poigenfurst J, Rappold G, Fischer W. Plating of fresh clavicular fractures: results of 122 operations. Injury 1992;23(4):237-41. 